\title{
Role of Growth Regulators in the Bean Hypocotyl Hook Opening Response
}

\author{
B. G. KANG and P. M. RAY \\ Department of Botany, University of Michigan \\ Received January 29/April .7, 1969
}

Summary. The opening of the hypocotyl hook in bean seedlings is due to a rapid elongation of cells on the inner side of the hook elbow. Red light promotes hook opening by inducing this cell elongation.

Opening is inhibited by low concentrations of indoleacetic acid (IAA) and 2,4-dichlorophenoxyacetic acid (2,4-D), and higher concentrations of these auxins cause a closure of the hook. In darkness, opening is induced slightly by $p$-chlorophenoxyisobutyric acid (PCIB), whereas in red light this auxin antagonist promotes opening only when IAA is added simultaneously to inhibit opening.

The amount of diffusible auxin released by the hook tissue is not affected by red illumination that is sufficient to induce maximal hook opening.

Gibberellio acid (GA) promotes the hook opening. The magnitude of its effect is, however, rather small, especially in darkness. (2-Chloroethyl)-trimethylammonium chloride (CCC) and $2^{\prime}$-isopropyl-4' $4^{\prime}$-(trimethylammonium-chloride)-5' -methylphenyl piperidine-1-carboxylate (Amo-1618) inhibit hook opening in red light, and this inhibition is completely overcome by addition of GA.

Cytokinins and abscisic acid at rather high concentrations inhibit hook opening in light but produce no significant effect in darkness.

Hook opening is promoted by $\mathrm{Ca}^{++}$and $\mathrm{K}^{+}$, and notably by $\mathrm{Co}^{++}$and $\mathrm{Ni}^{++}$.

It is concluded that 1 . endogenous gibberellin assists in hook opening, but light does not act by changing the gibberellin level; 2 . light does not act by decreasing the endogenous auxin level; and 3. cytokinins or abscisic acid do not seem to have a special role in the response.

\section{Introduction}

The terminal portion of the shoot axis of dark-grown seedlings in many dicotyledonous plants is shaped as a hook. In the hypocotyl of bean seedlings, opening of the hook is mediated by phytochrome (KuEIN et al., 1956; WiтHRow et al., 1957), exposure of the hook to red light bringing about opening, this effect being reversible by far-red light.

The light-induced hook opening is inhibited by both the presence of the terminal organs (i.e., intact hooks) and the addition of 3-indoleacetic acid (IAA) to excised hook segments. These observations led to the speculation that the terminal organs supply a diffusible auxin to the hook (KLEIN et al., 1956), and that this auxin prevents opening. Furthermore, the observation that an antiauxin induced hook opening in the absence of red light led to the hypothesis that red light acts by reducing the level of auxin in the hook (KLEIN, 1965). 
This paper presents results of an investigation of the hypothesis that light induces hook opening by influencing the hormonal balance of the hook tissue.

\section{Materials and Methods}

Plant Materials. 6-day-old dark-grown seedlings of Phaseolus vulgaris $\mathrm{L}_{\text {., }}$ ev. Black Valentine, were used. The seeds were planted in vermiculite in a plastic tray and germinated in complete darkness at $26 \pm 1^{\circ}$ and $70 \pm 2 \%$ relative humidity. Under a dim, green safelight the terminal organs were removed and the hook was cut at its apical end in such a way the initial angle of the hook was $0^{\circ}$, meaning that the hook was curved through an angle of $180^{\circ}$ from the direction of the straight portion of the hypocotyl.

Two principal methods were employed to incubate hooks for the experimenta] period, usually $24 \mathrm{hr}$, or $20 \mathrm{hr}$ in the case of continuous red illumination: a) 10 hooks with approximately 2 -cm shanks (basal ends) attached were placed on a double layer of filter paper in a $10 \mathrm{~cm}$ Petri dish containing $20 \mathrm{ml}$ of distilled water or test solution; b) 10 hooks with approximately $4-\mathrm{cm}$ shanks attached were placed vertically with their basal ends inserted in $1 \%$ agar in a dish. In the latter case, test substances were applied in an agar block which was placed on the apical cut surface of the hook. The set of hooks was then kept in a glass chamber (volume about 10 liters) to prevent the agar block from drying out but not interfere with red illumination. The hooks were shadowgraphed at the end of the test period, and the angle of opening was measured on the shadowgraphs. Results are given as mean angle of opening \pm standard error of the mean.

Illumination. The red-light source was a pair of 4-watt fluorescent lamps covered with 6 layers of red cellophane (DU PONT) which transmitted light above $600 \mathrm{~nm}$. The light intensity was $375 \mathrm{erg}^{\mathrm{cm}} \mathrm{sec}^{-1}$. All manipulations were carried out in a dim green safelight (WITHRow and PrICE, 1957). They were usually completed within $30 \mathrm{~min}$. Such exposure did not significantly affect subsequent hook opening.

Bioassay of Diffusible Auxin. Diffusible auxin from the hook was assayed by the Avena curvature test (WENT and THLNANN, 1937). In order to obtain appreciable, reproducible yields of diffusible auxin from the tissue, it was necessary to prevent enzymatic inactivation of auxin at the cut surface by using $0.005 \mathrm{M} \mathrm{KCN}$ (STEEVES et al., 1953). An agar block $(2.7 \times 2.7 \times 1.5 \mathrm{~mm}$ ) was attached to the basal cut surface of each hook for a 2-hour diffusion period in a water-vapor-saturated Petri dish in complete darkness and used for the test immediately after the diffusion period.

The distribution of elongation along the inner and outer surfaces of the hook (Fig. 1) was measured by applying a series of fine projecting lanolin "hairs" spaced about $2 \mathrm{~mm}$ apart along the two sides of an isolated hook standing with its base in agar. IAA, where administered, was applied in an agar block to the apical end. The marked hooks were shadowgraphed at the beginning and end of the 24-hr growth period, and the fractional change in distance between each of the marks was determined by measurements upon the shadowgraphs.

\section{Results}

Effects of Light and Auxin on Elongation. The distribution of elongation activity along the length of isolated hook segments, measured as described above, is illustrated in Fig. 1. Light induces a spectacular elongation on the inner side of the hook, and IAA inhibits this elongation. 


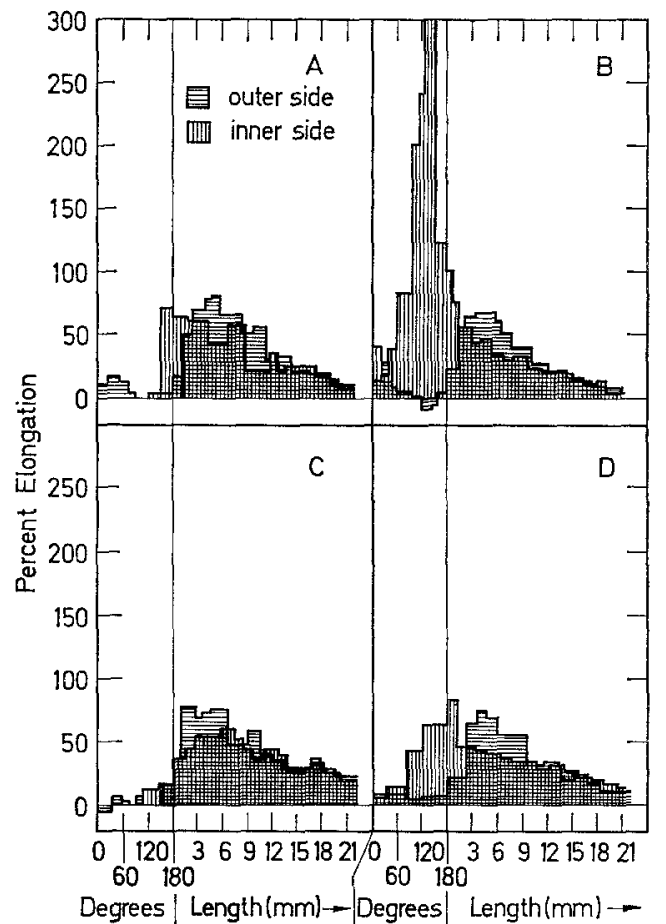

Fig. 1A-D. Distribution of elongation along the inner and outer sides of isolated hypocotyl hooks and the subjacent shank under treatment with darkness (A), red light (B), IAA $(0.5 \mu \mathrm{g} / \mathrm{ml})$ in darkness (C), and IAA plus red light (D). Abscissa; distance from apical end of the hypocotyl expressed in terms of degrees in hook portion considered as a semicircle $\left(0^{\circ}\right.$ meaning apical end, $90^{\circ}$ meaning vertical peak, and $180^{\circ}$ meaning basal end of the semicircle), and expressed in terms of length of the shank starting from the basal end of the hook

Photomicrographs were made from microtome sections cut from paraffin-embedded specimens of hook tissue that had been fixed at zero time and after $20 \mathrm{hr}$ in red light. By measurements on these photographs the mean lengths of cortical cells on the inside of the hook elbow region was estimated, and was found to be approximately 2.5 times greater after the light-induced period of hook opening. The agreement between this figure and the directly measured elongation on the inside surface of the hook elbow (Fig. 1) supports the statement of KLEIN (1959) that this growth response involves cell enlargement not accompanied by any appreciable cell division.

Results of treatment with different IAA concentrations are collected in Fig. 2. They show that IAA application specifically inhibits elongation 


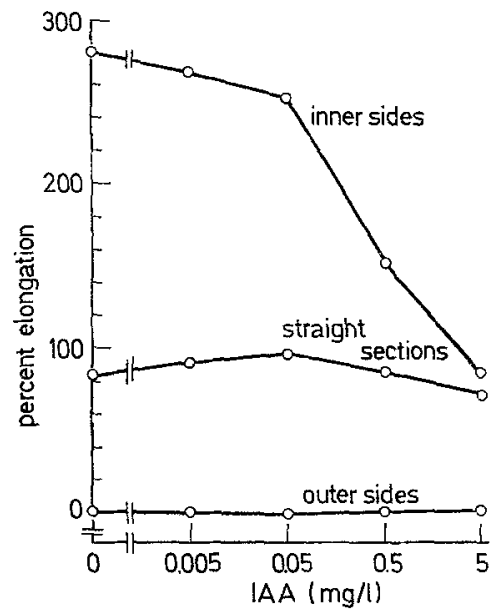

Fig. 2. Effect of IAA on elongation of the inner and outer sides of isolated segments of hook elbow and straight sections of the hypocotyl shank in red light for $24 \mathrm{hr}$

on the inner side of the hook and has little or no effect on elongation in the straight part of the hypocotyl or on the (slight) elongation of the outer side of the hook.

Fig. 3 shows dependence of opening angles on concentrations of IAA and 2,4-dichlorophenoxyacetic acid (2,4-D). Both these auxins strongly inhibit hook opening in red light and in darkness. The small discrepancy between the growth curve (Fig. 2) and the opening curve in terms of IAA concentrations is probably because of the different method employed in the latter case where hooks were placed in IAA solution in a Petri dish. Auxin concentrations above $1 \mathrm{mg} / \mathrm{l}$ induce a negative curvature, meaning that the hook becomes curved in the reverse of the normal direction of opening.

Fig. 4 shows that $p$-chlorophenoxyisobutyric acid (PCIB), an auxin antagonist, induces hook opening in darkness to a certain extent, but has no such effect in red light. KLEIN (1965) reported a similar effect of naphthylmethylsulfide acetate. When IAA was added in the medium in red light, PCIB partially reversed the IAA inhibition, the magnitude of its effect being somewhat greater than that in darkness without IAA (Fig. 4).

Effect of Light on the Yield of Diffusible Auxin. Results of bioassays of the diffusible auxin from the hook are summarized in Table 1. Red light had no significant effect on the amount of diffusible auxin released by the books. Neither pretreatment with red light from $1 \mathrm{hr}$ up to $16 \mathrm{hr}$ nor treatment with red light during the $2-\mathrm{hr}$ diffusion period caused any 


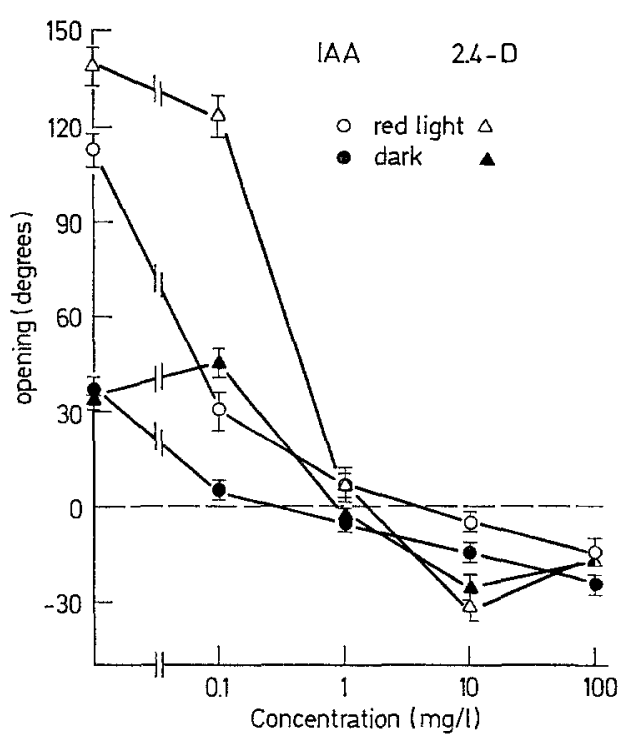

Fig. 3

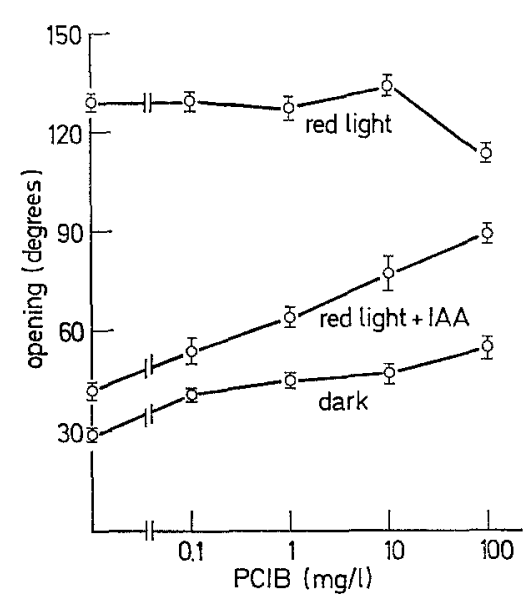

Fig. 4

Fig. 3. Effects of concentrations of IAA and 2,4-D on hook opening. Vertical bars represent the range of standard errors

Fig. 4. Effect of PCIB on hook opening in dark, red light, and red light plus IAA (0.1 mg/l)

appreciable difference in the yield of diffusible auxin compared with that from the dark control. The amount of diffusible auxin from excised hooks actually declines rapidly with time; $4 \mathrm{hr}$ after the excision the amount of diffusible auxin is almost nil in both red light and dark. When the terminal organs (cotyledons and shoot apex) were not removed, diffusible auxin could still be collected after $16 \mathrm{hr}$ of red light or dark treatment, indicating that the terminal organs are supplying auxin to the hypocotyl. The red-illuminated hooks opened about $45^{\circ}$ at $16 \mathrm{hr}$, whereas the dark hooks remained closed.

Involvement of Gibberellic Acid. As shown in Fig. 5, gibberellic acid (GA) promotes hook opening in red light but has little effect in darkness. We were completely unable to confirm the substantial induction of hook opening in the dark by very high concentrations $\left(10^{-3} \mathrm{M}\right)$ of gibberellin that was reported by KuEIN (1965). However, we found, as Table 2 indicates, that an effect of GA in darkness can be brought on bytreatment with PCIB.

KLEIN (1965) reported that the degree of hook opening is a function of shank length, and suggested that GA is transported acropetally and red light causes the GA transport. The data presented in Table 3 confirm 
Table 1. Effect of red light on the diffusible auxin yield of the hook tissue

\begin{tabular}{|c|c|c|c|}
\hline \multirow[t]{2}{*}{$\begin{array}{l}\text { Exp't. } \\
\text { No. }\end{array}$} & \multirow[t]{2}{*}{$\begin{array}{l}\text { Experimental } \\
\text { condition }^{a}\end{array}$} & \multicolumn{2}{|c|}{$\begin{array}{l}\text { Degrees of Avena curvature } \\
\text { (mean } \pm \text { standard error) }\end{array}$} \\
\hline & & Dark control & Red light \\
\hline 1 & $\begin{array}{l}\text { Excised hook. } 1 \mathrm{hr} \text { light treatment } \\
\text { followed by } 2 \mathrm{hr} \text { diffusion in dark }\end{array}$ & $15.0 \pm 0.82$ & $13.4 \pm 0.92$ \\
\hline 2 & $\begin{array}{l}\text { Excised hook. } 4 \mathrm{hr} \text { light treatment } \\
\text { followed by } 2 \mathrm{hr} \text { diffusion in dark }\end{array}$ & $2.1 \pm 1.11$ & $0.9 \pm 0.66$ \\
\hline 3 & $\begin{array}{l}\text { Excised hook. } 2 \mathrm{hr} \text { light treatment } \\
\text { during diffusion period }\end{array}$ & $14.2 \pm 0.54$ & $14.2 \pm 0.73$ \\
\hline 4 & $\begin{array}{l}\text { Intact hook with terminal organs. } \\
16 \mathrm{hr} \text { light treatment followed } \\
\text { by } 2 \mathrm{hr} \text { diffusion in dark }\end{array}$ & $17.0 \pm 1.11$ & $15.9 \pm 1.01$ \\
\hline 5 & $\begin{array}{l}\text { Excised hook. } 4 \mathrm{hr} \text { light treatment } \\
\text { with IAA }(10 \mathrm{mg} / 1) \text { in agar block. } \\
\text { Agar block removed at end of the } \\
4 \mathrm{hr} \text {. Diffusion in dark for sub- } \\
\text { sequent } 2 \mathrm{hr}\end{array}$ & $18.3 \pm 0.28$ & $18.3 \pm 1.26$ \\
\hline
\end{tabular}

a Red light intensity, $9400 \mathrm{erg} \mathrm{cm}^{-2} \mathrm{sec}^{-1}$.

$\mathrm{b} 0.05 \mathrm{mg} / \mathrm{l}$ IAA in agar block yielded curvature of $16.7 \pm 1.04$, and $0.25 \mathrm{mg} / \mathrm{l}$ IAA yielded $26.6 \pm 2.12$.

c Red light treated hook opened about $45^{\circ}$ at $16 \mathrm{hr}$.

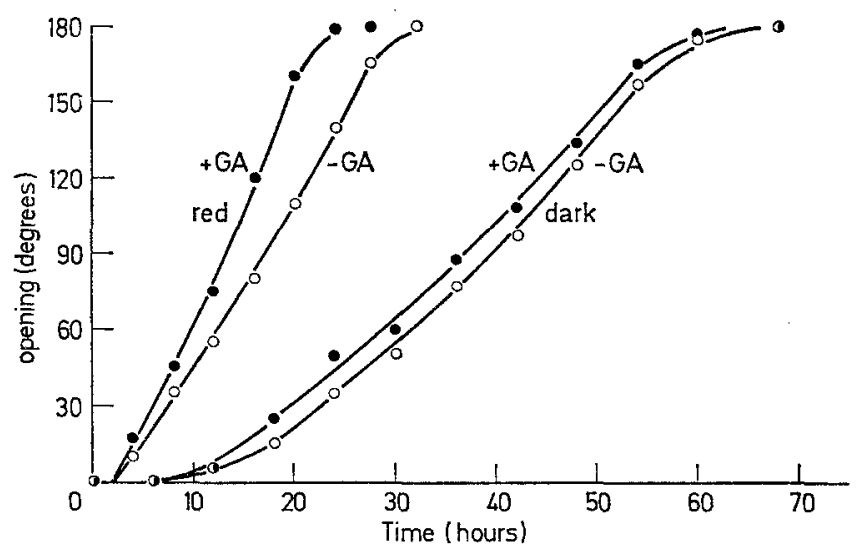

Fig. 5. Time course of opening in red light and dark, with and without GA (0.055 ug per hook)

his observations that hook sections with longer shanks opened to a greater extent than those with shorter shanks. However, the Table also shows that a saturating concentration of GA (cf. Fig. 6) causes equal 
Table 2. Enhancement of $G A$ response by PCIB

Hook opening, degrees.

\begin{tabular}{lrrll}
\hline Condition & \multirow{2}{*}{$\mathrm{H}_{2} \mathrm{O}$} & \multicolumn{1}{c}{$\mathrm{GA}$} & $\begin{array}{l}\text { PCIB } \\
(10 \mathrm{mg} / \mathrm{l})\end{array}$ & $\begin{array}{l}\text { GA }(10 \mathrm{mg} / \mathrm{mg} / \mathrm{l}) \\
+ \text { PCIB }(100 \mathrm{mg} / 1)\end{array}$ \\
\hline Dark & $16 \pm 2.9$ & $24 \pm 3.5$ & $36 \pm 2.5$ & $67 \pm 2.5$ \\
Red light & $120 \pm 2.9$ & $143 \pm 1.8$ & $94 \pm 3.8$ & $123 \pm \mathbf{3 . 0}$ \\
\hline
\end{tabular}

Table 3. Effects of the shank length and $G A$ on hook opening in red light

Figures show hook opening in degrees \pm standard error of the mean.

\begin{tabular}{lrl}
\hline $\begin{array}{l}\text { Shank } \\
\text { length } \\
(\mathrm{cm})\end{array}$ & \multicolumn{1}{l}{ GA $(\mathrm{mg} / \mathrm{l})$} & \\
\cline { 2 - 3 } & 0 & 20 \\
\hline 3 & $91 \pm 1.6$ & $121 \pm 2.3$ \\
8 & $121 \pm 3.1$ & $166 \pm 1.7$ \\
\hline
\end{tabular}

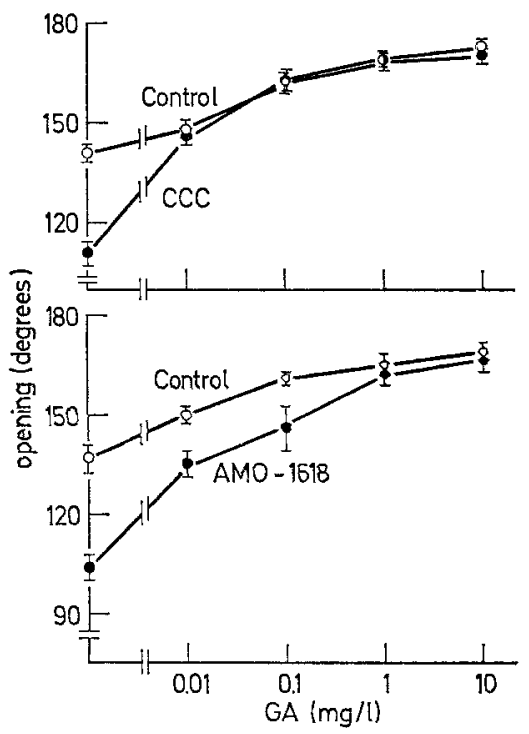

Fig. 6. Reversal of CCC and Amo-1618 inhibitions of hook opening by GA in red light. CCC $\left(10^{-2} \mathrm{M}\right)$ and GA were applied in solution simultaneously to the hooks. Plants were pretreated on the 3rd day of germination with Amo-1618 (200 mg/l) in a soil drench and GA was later applied to the hooks

promotions of opening when given to hooks with short and long shanks, indicating that the effect of the shank cannot be ascribed to its providing a source of GA. 


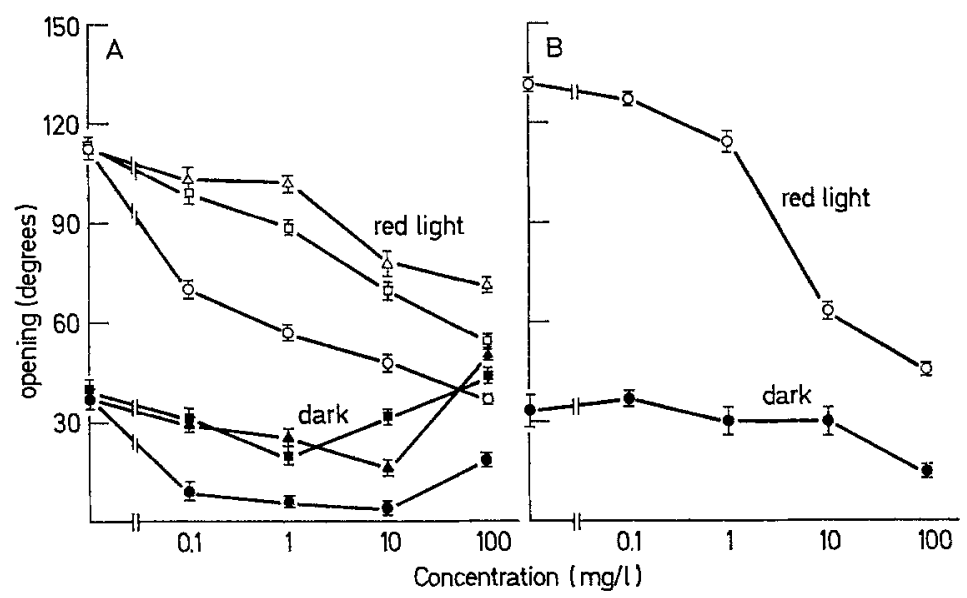

Fig. $7 \mathrm{~A}$ and B. Effects of cytokinins (A) and abscisic acid (B) on hook opening ○ Benzyladenine; $\triangle$ Pyranosylated Benzyladenine; $\square$ 6-Furfurylaminopurine

The growth retardants (2-chloroethyl)trimethylammonium chloride (CCC) and 2'-isopropyl-4'-(trimethylammonium chloride)-5'-methylphenyl piperidine-1-carboxylate (Amo-1618), which inhibit GA synthesis (Harada and Latig, 1965; Dennis et al., 1965), reduce hook opening in red light. This inhibition can be completely overcome by addition of GA in the medium (Fig. 6).

Effects of Other Growth Regulators. 6-furfurylaminopurine (kinetin), benzyladenine, and pyranosylated benzyladenine have inbibitory effects on hook opening in red light, but very slight effects in darkness (Fig. 7 A). Cytokinin treatment did not relieve the inhibition of hook opening by auxins.

Abscisic acid inhibited hook opening at fairly high concentrations (Fig. $7 \mathrm{~B}$ ). Tested at $10 \mathrm{mg} / \mathrm{l}$ abscisic acid did not reduce the promotive effect of $10 \mathrm{mg} / \mathrm{l} \mathrm{GA}$ nor the inhibitory effect of $0.1 \mathrm{mg} / \mathrm{l} \mathrm{IAA}$.

Effect of Cations. $\mathrm{Co}^{++}$, as found previously by $\mathrm{K}$ uEN (1959), and $\mathrm{Ni}^{++}$promote hook opening both in red light and in darkness (Fig. 8). At $10^{-3} \mathrm{M}$ these cations induce hook opening in darkness quite dramatically. Higher concentrations are inhibitory in both light and darkness.

Time-course measurements (Fig. 9) showed that the promotive effect of $\mathrm{Co}^{++}$is exerted on the initial phase of the response and that even at the optimally promotive concentration $\mathrm{Co}^{++}$gradually becomes inhibitory and prevents attainment of complete straightening of the hook. However, $10^{-3} \mathrm{M} \mathrm{CoCl}_{2}$ in darkness cause initially as rapid a rate of hook opening as can be induced by treatment with red light. Even so, the $\mathrm{Co}^{++}$-induced hook opening can initially be further promoted substantially by red light (see Fig. 9), and it appears from these data that the reduced red- 


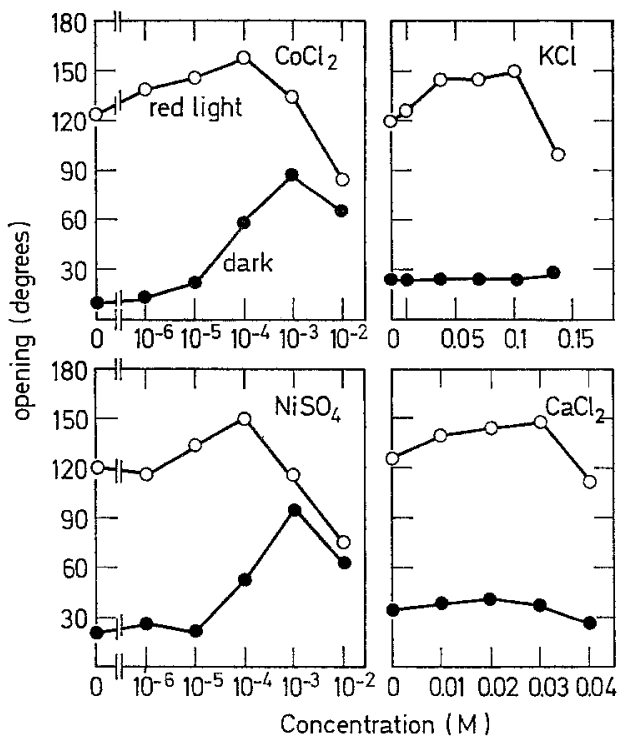

Fig. 8. Effects of some cations on hook opening

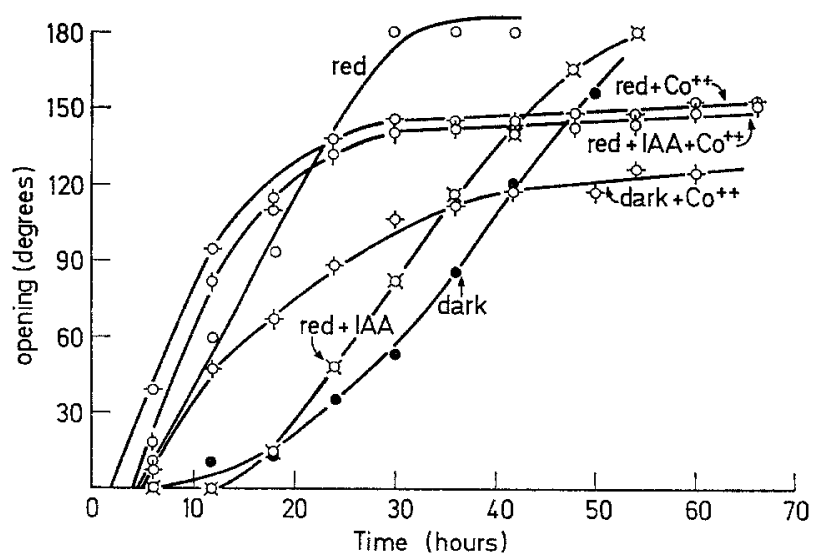

Fig. 9. Time course of hook opening under a combination of $10^{-3} \mathrm{M} \mathrm{CoCl}_{2}$ and $2 \mathrm{mg} / \mathrm{l}$ IAA

light response recorded at the optimal $\mathrm{Co}^{++}$concentration in Fig. 8 is actually due to the later, inhibitory effect of $\mathrm{Co}^{++}$on hook opening. These observations supplement the finding of KuIIN (1959) that $\mathrm{Co}^{++}$interacts synergistically with red light in this response.

$\mathrm{Ca}^{++}$and $\mathrm{K}^{+}$exert a small but consistent stimulation of hook opening in light, but unlike $\mathrm{Co}^{++}$and $\mathrm{Ni}^{++}$they do not induce opening in darkness 
Table 4. Effects of salts on hook opening responses to $G A$ and IAA

Figures given in the first two horizontal rows are the average results from three separate experiments, all of which showed comparable promotions by $\mathrm{Ca}^{++}$and $\mathrm{GA}$ and a comparable arrest of these promotions under the combination (Ca++ $+\mathrm{GA})$. Results in the remaining rows are from single experiments.

\begin{tabular}{|c|c|c|c|}
\hline \multirow[t]{2}{*}{ Treatment } & \multirow[t]{2}{*}{ Control } & \multicolumn{2}{|c|}{ Hook opening, degrees } \\
\hline & & $\begin{array}{l}\mathrm{GA} \\
(10 \mathrm{mg} / \mathrm{l})\end{array}$ & $\begin{array}{l}\text { IAA } \\
(0.1 \mathrm{mg} / \mathrm{l})\end{array}$ \\
\hline Red light & 126 & 154 & 45 \\
\hline Red light, $0.03 \mathrm{M} \mathrm{CaCl}_{2}$ & 140 & 119 & 83 \\
\hline Red light, $0.01 \mathrm{MnCl}_{2}$ & 89 & 143 & 34 \\
\hline Red light, $0.01 \mathrm{M} \mathrm{LiCl}$ & 49 & 87 & 21 \\
\hline Dark & 30 & 33 & -3 \\
\hline $\mathrm{CoCl}_{2} 0.001 \mathrm{M}$ in dark & 90 & 92 & 92 \\
\hline $\mathrm{NiSO}_{4} 0.001 \mathrm{M}$ in dark & 95 & 103 & 59 \\
\hline
\end{tabular}

(Fig. 8). $\mathrm{Na}^{+}, \mathrm{Li}^{+}, \mathrm{Mn}^{++}$and $\mathrm{Mg}^{++}$had no appreciable effect on hook opening in light or dark at concentrations up to $10^{-3} \mathrm{M}$; $\mathrm{Li}^{+}$and $\mathrm{Mn}^{++}$ were inhibitory at $10^{-2} \mathrm{M}$ (cf. Table 4) whereas $\mathrm{Na}^{+}$and $\mathrm{Mg}^{++}$were not.

When the effects of these cations upon the response to growth regulators were tested some striking results were obtained, as illustrated in Table 4 which summarizes data from a number of experiments. $\mathrm{Ca}^{++}$, at a concentration optimally promotive of hook opening, completely suppressed the promotive effect of GA on the process, and indeed in the presence of $\mathrm{Ca}^{++}, \mathrm{GA}$ became somewhat inhibitory. The data can also be viewed as saying that $\mathrm{GA}$ prevents the promotive effect of $\mathrm{Ca}^{++} . \mathrm{Mn}^{++}$ and $\mathrm{Li}^{++}$, on the other hand, did not prevent the promotive effect of GA, and it even appeared that GA essentially reversed the inhibitory effect of $\mathrm{Mn}^{++}$. None of these ions prevented the inhibitory effect of IAA, but $\mathrm{Co}^{++}$completely blocked and $\mathrm{Ni}^{++}$greatly reduced the effect of IAA. This effect of $\mathrm{Co}^{++}$was seen both in darkness (Table 4) and in red light (Fig. 9).

Inhibition by Mannitol. The effect of mannitol on hook opening in red light is shown in Fig. 10. Inhibition occurs in the osmotic concentration range and the inhibition curve resembles rather closely that for growth of pea stem segments (Thimann et al., 1950). In view of Fig. 10 it is remarkable that 0.2 osmolar $(0.1 \mathrm{M}) \mathrm{KCl}$ and 0.1 osmolar $(0.03 \mathrm{M})$ $\mathrm{CaCl}_{2}$ promoted rather than inhibited hook opening (Fig. 8). Galactose and mannose, at $0.03 \mathrm{M}$, inhibited hook opening only to about the same extent $(10-25 \%)$ as an equal concentration of mannitol.

\section{Discussion}

The responses to IAA, GA and kinetin of the bean hypocotyl hook are, in general, similar to those of the etiolated pea epicotyl hook (NAKAMURA 


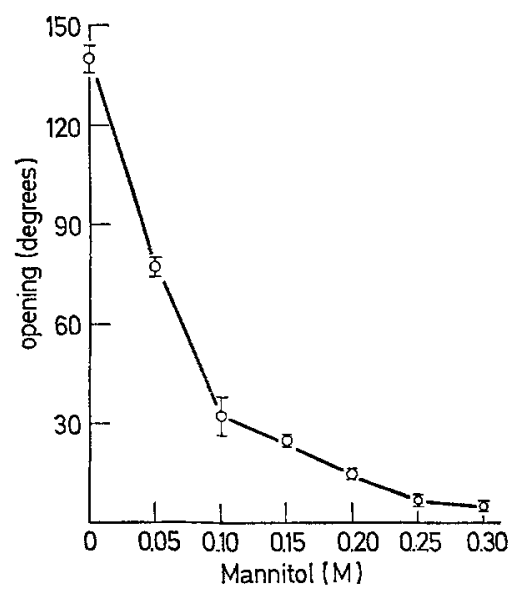

Fig. 10. Inhibition of hook opening in red light by mannitol

et al., 1966), except that auxin-treated bean hooks do not noticeably enlarge in the transverse direction. Also, Nakamura and TAKaHasmi (1968) reported that PCIB inhibits pea hook elongation, whereas this auxin antagonist promotes bean hook opening and reduces the inhibition thereof by IAA.

Any hypothesis that increase in gibberellin content is the factor responsible for light-induced opening of hooks can be ruled out by the small effect of GA applied in the darkness. However, the inhibitory effects of CCC and Amo-1618 and their reversal by GA suggest that gibbercllin is required for the growth that is involved in light-induced hook opening. Similar results with CCC were obtained for pea epicotyl hooks by NaKamuka and TakaHashr (1968).

There are some indications that seem to support the hypothesis that red light acts on opening by reducing the level of endogenous auxin. These include a) the opposing effect of auxin and red light on hook opening; b) the promotion of hook opening by removing cotyledons and plumule (KIEIN et al., 1956), which as shown here are the major source of auxin for hook tissue; c) the induction of opening by PCIB in darkness; d) the enhancement of the GA effect by PCIB in darkness, and by red light, but not by PCIB in red light; e) the promotion of hook opening by longer shanks which might use up or draw more of the endogenous auxin from the hook, and f) the reduction of the auxin level by red irradiation in bean seedlings reported by FLETCHER and $Z_{A L I K}$ (1964).

However, it seems quite clear from the results of the assays for diffusible auxin that there is no direct correlation between red light and yields of diffusible auxin from the hook tissue. Red light treatment that 
is sufficient to induce substantial opening of hooks did not significantly change the amount of diffusible auxin collected from the hook elbow tissue. The dramatic promotive effect of light on opening of excised hooks extends over a period of $24 \mathrm{hr}$ or more even though the yield of diffusible auxin of such hooks has fallen to nil after about $4 \mathrm{hr}$; whereas light induces opening of intact hooks bearing cotyledons and plumule even though their yield of diffusible auxin remains substantial after many hours and is still unaffected by light. It seems certain, therefore, that the opening behavior of the hook is not determined simply by its level of diffusible auxin, and that light does not induce hook opening by causing a decrease in this level. It can be asked, of course, whether red light affects a kind of auxin other than the diffusible form. The depression of auxin content that was reported by FLETCHER and ZALIK (1964) in bean seedlings after red irradiation, was measured in terms of total methanol extractable IAA. The prevalent view today, however, is that diffusible auxin is the physiologically active hormone (GILLESPIE and Thrmann, 1963; Pickard and Thimann, 1964).

It may be surmised, however, that the eventual slow opening of excised hooks in darkness results from depletion of their endogenous auxin whereas the rapid opening in red light is attributable to some other mechanism. Opening of excised hooks in darkness is not due merely to a loss of responsivity to auxin. This is shown by the observation that when IAA was applied to hooks in the dark $24 \mathrm{hr}$ after excision, it still prevented opening.

The various lines of evidence about the relation between auxin and the red light response might be reconciled at least in part by the hypothesis that light decreases the sensitivity of hook cells towards inhibition of growth by auxin. Such a hypothesis was advanced by BRAUnER (1966) in an effort to explain the effect of gravity in geotropism. This kind of hypothesis, which is difficult to test directly, seems to be needed as a result of findings regarding the involvement of ethylene in the response (see KANG and RAY, 1969a). The participation of ethylene also affords an explanation for the remarkable effects of $\mathrm{Co}^{+++}$and $\mathrm{Ni}^{++}$on hook opening and on its response to IAA.

The curious effects of $\mathrm{Ca}^{++}$and $\mathrm{Mn}^{++}$that were observed on the response to GA suggests that the effect of GA on this system may involve ion relations of the growing cells. Aspects of the response to GA are considered further by KANG and RAY (1969b).

\section{References}

Brauner, L.: Versuche zur Analyse der geotropischen Perzeption. V. Über den Einfluß des Schwerefeldes auf die Auxinempfindlichkeit von HelianthusHypokotylen. Planta (Berl.) 69, 299-318 (1966). 
Dennis, D. T., C. D. Upper, and C. A. West: An enzymic site of inhibition of gibberellin biosynthesis by Amo 1618 and other plant growth retardants. Plant Physiol. 40, 948-952 (1965).

FLETCher, R. A., and S. ZaliK: Effect of light quality on growth and free indoleacetic acid content in Phasealus vulgaris. Plant Physiol. 99, 328-331 (1964).

GLLLESPIE, B., and K. V. ThumanN: Transport and distribution of auxin during tropic response. I. The lateral migration of auxin in geotropism. Plant Physiol. $38,214-225$ (1963).

HaraDA, H., and A. LANG: Effect of some (2-chloroethyl) trimethylammonium chloride analogs and other growth retardants on gibberellin biosynthesis in Fusarium moniliforme. Plant Physiol. 40, 176-183 (1965).

KANG, B. G., and P. M. RAY: Ethylene and carbon dioxide as mediators in the response of the bean hypocotyl hook to light and auxins. Planta (Berl.) 87, $206-216$ (1969a).

- - Effects of inhibitors of RNA and protein synthesis on bean hypocotyl hook opening and their implications regarding phytochrome action. Planta (Berl.) 87, 217-226 (1969b).

KIEIN, R. M.: Photomorphogenesis of the bean plumular hook. Physiol. Plantarum 18, 1026-1033 (1965).

KLEIN, W. H.: Interaction of growth factors with photoprocess in seedling growth. In: Photoperiodism and related phenomena in plants and animals (R. B. WiтHRow, ed., p. 207-215), Washington, D.C.: AAAS 1959.

- R. B. Withrow, and V. B. Elstad: Response of the hypocotyl hook of bean seedlings to radiant energy and other factors. Plant Physiol. 31, 289-294 (1956).

NAKAMURA, T., and N. TAKAHASHI: The role of auxin in growth of the plumular hook section of etiolated pea seedling. Plant and Cell Physiol. 9, 681-688 (1968).

- T. Yamada, and N. TakahashI: Effect of gibberellic acid on growth of the plumular hook section of etiolated pea seedling. Bot. Mag. (Tokyo) 79, 404-413 (1966).

Prckard, B. G., and K. V. Thimans: Transport and distribution of auxin during tropic response. II. The lateral migration of auxin in phototropism of coleoptiles. Plant Physiol. 39, 341-350 (1964).

Steeves, T. A., G. Morel, and R. H. WerTMORE: A technique for preventing inactivation at the eut surface in auxin diffusion studies. Amer. J. Bot. 40, $534-538$ (1953).

Thimann, K. V., R.R. Statee, and G. S. Christiansey: The metabolism of stem tissue during growth and its inhibition. IV. Growth inhibition without enzyme poisoning. Arch. Biochem. 28, 130-137 (1950).

Went, F. W., and K. V. Thrmans: Phytohormones. New York: The Macmillan Co. 1937.

Withrow, R. B., W. H. KuEIN, and V. ELSTAD: Action spectra of photomorphogenic induction and its photoinactivation. Plant Physiol. 32, 453-462 (1957).

-, and L. Price: A darkroom safelight for research in plant photobiology. Plant Physiol. 32, 244-248 (1957).

Dr. BIN G. KaNG

MSU/AEC Plant Research Laboratory

Michigan State University

East Lansing, Michigan 48823, USA.
Dr. Peter M. Ray

Department of Biological Sciences

Stanford University

Stanford, California 94305, USA. 